\title{
ONDE MORAM OS PRECARIZADOS: A INTERLOCUÇÃO ENTRE PRECARIZAÇÃO DO TRABALHO E ESTIGMA TERRITORIAL
}

\author{
Where the precarious ones live: the interlocution between precarious \\ work and territorial stigma
}

Silvia Adriana Lima Corrêa'

\begin{abstract}
Resumo
Este artigo trata de estudo empreendido entre os anos de 2015 e 2017 numa localidade demarcada como o "lugar perigoso" de uma pequena comunidade aqui mencionada pelo nome fictício de "Santa Clara", zona sul da cidade de Manaus. Propõe-se discutir sobre a interlocução existente entre as atuais figurações de trabalhador precário impostas às camadas populares e a reprodução de estigmas territoriais que recaem sobre áreas habitadas por esses segmentos. No contexto da localidade estudada, observou-se a centralidade da categoria trabalho na reprodução de tal estigma, na medida em que as diferentes relações que os moradores desenvolvem com essa categoria, possibilitam estratégias de fuga da desclassificação social. Isso porque, por serem moradores de um lugar considerado destinado a toda espécie de "gente que não presta", a adequação ao mercado formal de trabalho converte-se numa espécie de atributo de "capacidade" e "honradez", compreensão que lhes permite o estabelecimento de critérios de distinção e de escalas hierárquicas de (des) classificação grupal que culminam na valorização de alguns subgrupos, em detrimento de uma grande maioria marginalizada, considerada inapta ao mercado de trabalho formal. A figuração "trabalhador" aparece, então, no contexto do discurso neoliberal vigente reproduzido no lugar, como elemento de distinção e não de unidade, dinâmica que reforça a marginalização da grande maioria sem acesso ao mercado formal de trabalho, que apareceu em campo na figura do desocupado. Por implicação, a mesma dinâmica permite que o estigma territorial de "lugar perigoso" que afeta a localidade, seja reforçado por dentro, pela atuação dos próprios moradores.
\end{abstract}

Palavras-chaves: Trabalhador precarizado; Desclassificação social; Estigma territorial.

\begin{abstract}
This article deals with a study undertaken between the years 2015 and 2017 in locality marked as the "dangerous place" of a small community here called by of "Santa Clara", south zone of the city of Manaus. It is proposed to discuss an interlocution between the precarious work figures imposed on the popular ones and a reproduction of territories that demand on the areas inhabited by these segments. In the context of the studied locality, the centrality of the category of work in the reproduction of such stigma was observed, since the different relations that the residents develop with this category, allow strategies of escape of the social declassification. This is because, they are residents of a place considered as destined for all sorts of "people who not pay", adaptations to the formal labor market becomes a kind of attribute of "capacity" and "honesty", an understanding that allows them to the
\end{abstract}

\footnotetext{
1 Doutoranda em Sociedade e Cultura na Amazônia pela Universidade Federal do Amazonas (Ufam) Manaus, Brasil. E-mail: silviadric@hotmail.com.
} 
establishment of criteria of distinction and hierarchical scales of (dis)group classification that culminate in the valuation of some subgroups, to the detriment of a large majority marginalized, considered inapt to the formal job market. The "worker" figuration appears then in the context of the current neoliberal discourse reproduced in the place, as an element of distinction and not of unity, a dynamic that reinforces the marginalization of the great majority without access to the formal labor market, which appeared in the field in the figure of the unemployed. By implication, the same dynamic allows the territorial stigma of "dangerous place" that affects the locality, is reinforced inside, by the action of the own residents.

Keywords: Precarious worker; Social disqualification; Territorial stigma.

\section{Introdução}

O estudo da categoria "trabalho" constante neste artigo corresponde apenas a uma dimensão de análise mais ampla que compôs meu trabalho de dissertação de mestrado, em pesquisa empreendida entre os anos 2015 e 2017 pelo Programa de Pós-Graduação em Sociologia da Universidade Federal do Amazonas (UFAM). Na ocasião, a necessidade de compreender o caso de uma localidade manchada pelo estigma de "lugar perigoso", situada às margens de um igarapé que entrecorta uma das comunidades do bairro Petrópolis, zona sul da cidade de Manaus me fez mergulhar no cotidiano daqueles sujeitos sociais. Problema de pesquisa, aliás, observado ainda em minha experiência de iniciação científica entre 2012 e 2013, dado ao fato de, a despeito de estudar as condições materiais de moradia desse lugar caracterizado por sua precarização, ter percebido que um aspecto imaterial sobressaia de forma concomitante à materialidade do processo acelerado de degradação do entorno daquele igarapé que entrecorta a comunidade, aqui tratada pelo nome fictício de "comunidade Santa Clara"2. Refiro-me ao processo constante e latente de deterioração da imagem do "morador do igarapé" na pequena comunidade, identificado em um conjunto de narrativas de uso frequente, inclusive, entre os próprios moradores. As práticas de julgamento em relação a esse grupo social identificadas por mim em campo, apresentavam-se em ordem sempre ascendente: as narrativas começavam por caracterizá-los como "negligentes” com o lugar de moradia,

\footnotetext{
2 Não apenas a comunidade é referenciada nesta a partir de um nome fictício, mas todos os interlocutores que contribuíram para a produção deste estudo, assim como todos os indivíduos citados indiretamente. Também não será identificado o nome do igarapé, embora um conhecedor da cidade possa identificar que trata de um dos igarapés pertencentes à bacia de Educandos que perpassa essas imediações.
} 
quando tratados como "imundos", e culminavam em sua criminalização de forma generalizada, quando classificados como "bandidos".

A pequena localidade é apenas um recorte espacial pertencente à comunidade Santa Clara, situada no bairro Petrópolis, zona sul da cidade de Manaus. Geralmente designada pelos moradores de outras localizações como o lugar onde "só tem gente que não presta", o "lugar perigoso" da comunidade. O Bodozal3 , nome pelo qual é designado o "lugar perigoso", é um exemplo emblemático de como os simbolismos afetam de forma concreta a produção das realidades, tornando "verdades" informações que sequer requerem prévias reflexões para assim figurarem. A partir de uma análise relacional, observaram-se dois grupos que se destacaram em campo antagonicamente: os moradores das ruas da parte alta da comunidade, associados à sua área "boa para morar"; e os moradores dos becos, na baixada, à margem do igarapé, residentes na localidade "degradada" da comunidade.

É nesse universo de informações que se fez necessário desenvolver a discussão sobre as figurações possíveis de grupos sociais existentes na localidade em questão, para além do plano da aparência, possibilitando a aproximação da complexidade do lugar, até então visto previamente de forma generalizante e unívoca. Foi seguindo esse roteiro que me inseri nas interações e percepções locais da baixada, e o que tornou possível chegar à conclusão que a forma como os moradores se relacionavam com o trabalho operava entre eles mesmos como um dos critérios de (des)classificação social. Implica em dizer que, por se constituir um lugar de moradia popular percebido por seu entorno como um "reduto dos párias", estar associado ao trabalho podia significar para aqueles moradores como uma boa estratégia para a fuga da desclassificação social. Ficou patente que a relação dos moradores com o trabalho correspondia a uma dimensão do processo de reprodução do estigma territorial que se sustentava, então, por dentro, pela atuação dos próprios moradores do lugar estigmatizado.

\footnotetext{
${ }^{3}$ A palavra bodozal é usada em forma de zombaria, pois reporta ao nome de um peixe da região, caracterizado por ter a casca grossa e viver em áreas alagadas, conhecido por Acari Bodó, termo esse empregado para ilustrar a condição de quem vive nessas imediações que, assim como o peixe, vive na lama.
} 
Por meio das argumentações aqui trazidas defende-se que a condição de trabalhador precarizado, em suas diferentes segmentações, se insere nas escalas de classificação social, proporcionando um processo (des)valorativo do sujeito e de sua aceitação social pelos seus pares como alguém de "respeito" ou não. Isso será evidenciado ao tratar da forma como os moradores são percebidos entre si, por meio de escalas descendentes que são formadas entre as figurações trabalhadores formais e informais, até chegar à camada considerada a mais inferior diante das demais: os "desocupados" - leva de indivíduos inaptos para o mercado de trabalho formal em suas mais diferentes variações, inclusive, aqueles inseridos em atividades ilícitas, considerados os mais desclassificados naquele contexto. As diferentes relações com o trabalho e figurações de trabalhadores delas decorrentes, utilizadas enquanto estratégia para fuga da desclassificação social, torna possivel depreender que o termo "trabalhador" no contexto dos valores neoliberais vigentes, opera mais como um elemento de diferenciação grupal do que necessariamente de formação de uma identidade coletiva, usase mais para separar os individuos entre os menos ou mais valiosos, do que para a construção de uma unidade.

No contexto de minha pesquisa de mestrado, essas inferências permitiram depreender que a sociodinâmica em questão contribuía para a reprodução e reafirmação do estigma territorial imputado ao lugar. Isso porque, a despeito das diferenças que pudessem ser demarcadas nos processos de comunicação, este é um dado que os assemelhava: a proximidade territorial, quer dizer, o pertencimento a um lugar reconhecido socialmente como um reduto de "vagabundos". Compreensão que se fortalece a medida que essas relações de alteridade se reproduzem. Além disso, esse tipo de lugar tem sua peculiaridade no contexto da cidade de Manaus: há todo um simbolismo pejorativo associado a ser morador do entorno do igarapé.

Áreas de entorno de igarapés onde ainda existem moradias, são caracterizadas pela precarização urbana, ocupadas irregularmente pelos segmentos populares de forma mais intensa a partir de meados da década de 1970 e 1980, no bojo do processo de metropolização da cidade. Os 
moradores de margens dos igarapés de Manaus parecem ser projetados mentalmente como uma espécie de extensão da imagem atual desses cursos d'água, hoje resumidos a grandes esgotos a céu aberto. Ambos se fundem e formam um "lugar", um ambiente que destoa (ao menos em tese e discurso político) do projeto de cidade que a elite atual diz pretender. Corresponde ao tipo de área que pode ser considerada como um enclave de trabalhadores precarizados, conforme veremos algumas linhas abaixo.

$\mathrm{Na}$ pesquisa em questão não foram considerados apenas dados obtidos de maneira direta, a partir de aplicação de questionário ${ }^{4}$ e entrevistas (embora também os tenha utilizado), mas aqueles advindos de um recurso etnográfico, ou seja, de observações do cotidiano, de conversas informais, que permitiram compreender a forma como as pessoas interagem umas com as outras e como se percebem entre si. Importa esclarecer que por ser conhecedora e conhecida na área, pude circular naturalmente sem causar maiores estranhamentos e dissimulações no interagir do cotidiano local, guardados os devidos cuidados epistemológicos de estranhamento do familiar. Foram ao todo 04 grupos familiares, os entrevistados de forma direta, que deveriam expressar o contraste das perspectivas do morador da parte alta e do morador da baixada, nos becos. Entretanto, neste artigo são evidenciados especificamente as observações que tratam das narrativas e interações dos moradores da baixada, considerado o "lugar perigoso" da comunidade Santa Clara.

Como aporte teórico central, foi importante considerar os processos de estigmatização por Norbert Elias e Bourdieu (2007) ${ }^{5}$, ao compreenderem tais processos inseridos no escopo das relações de poder e das relações de força entre classes por meio das violências simbólicas, respectivamente. Ambos os autores partem do principio, cada um a seu modo, de que é no microcosmo

\footnotetext{
4 Foi utilizado questionário com perguntas fechadas e abertas, proporcionando que o momento de interação direta com os interlocutores se caracterizasse como um diálogo na maioria do tempo. Seguimos o roteiro de entrevista como base, embora outros elementos fossem surgindo durante o diálogo, para que o interlocutor desfocasse da relação pesquisador-entrevistado que sugere uma relativa relação de poder. Importa informar, entretanto, que grande parte das inferências desta pesquisa não é atribuída a esse contato direto, mas ao recurso etnográfico de observação do cotidiano, uma vez que sendo moradora da comunidade, pude presenciar as interações sociais entre os comunitários sem as possiveis dissimulações implicadas no momento das entrevistas.

5 O processo de estigmatização é o "que todo grupo produz ao fixar indivíduos em classes hierarquizadas” (BOURDIEU, 2007, p.27)
} 
do mundo social que se sustentam as assimetrias sociais, sendo estas inscritas nas práticas cotidianas de reconhecimento e diferenciações intergrupais. Esta pesquisa se filiou a esse roteiro analítico, não negligenciando, porém, o fato deste estudo tratar de uma problemática urbana dentro de uma região tão peculiar em relação ao mundo, como é a região Amazônica. Outros autores também estão presentes na discussão que envolve a "Amazônia", enquanto construção analítica, e a cidade de Manaus, cujas demandas destacaram-se no decorrer da pesquisa: Silva (1996) ao demonstrar que a compreensão sobre o trabalho como um elemento valorativo se deu no contexto do processo civilizador dos povos amazônicos, o que pode pôr-nos a pensar quanto ao uso dessa categoria como uma dimensão ontológica do constitutivo humano; Scherer (2004) no que diz respeito à condição atual de informalidade de segmento da classe trabalhadora manauara. Há outros autores importantes que em algum aspecto contribuem para essa discussão, além das demais contribuições que são resultado de nossa experiência etnográfica.

\section{A interlocução entre a precarização do trabalho e moradia precária}

Nas localizações da baixada da comunidade Santa Clara, espaço reconhecido como o "lugar perigoso", o que se tem é um "emaranhado" de casas - um beco leva a outros tantos e estes formam uma espécie de labirinto no entorno do igarapé. Ao caminhar rumo ao bodozal, observa-se que em um dos becos há uma estreita entrada para uma viela, separada apenas pelas paredes das casas, cuja largura parece não ultrapassar a medida de um metro. Pode-se observar pela manhã, algumas pessoas saindo desse beco para trabalhar, quando terão que fazer o trajeto inverso ao que estou fazendo - acabo de descer uma das ladeiras que conduzem à baixada, é um percurso de aproximadamente $1 \mathrm{~km}$, rumo a uma grande avenida, onde passam os ônibus. São trabalhadores com diferentes destinos e ocupações: há desde aqueles que saem para trabalhar vestidos de bermuda e chinelo e que desenvolvem atividades laborativas como pedreiros, ajudantes de pedreiro, flanelinhas, pintores, trabalhadoras domésticas, além de outros profissionais do mercado informal como camelôs, vendedores 
ambulantes que há em grande número na localidade. Indivíduos para quem a condição de "trabalhador" não extingue a possibilidade de sua estigmatização, uma vez que ocupam na divisão social do trabalho um espaço considerado desprivilegiado socialmente.

É bastante evidente na localidade que a maioria dos moradores adultos estão inseridos no mercado informal de trabalho. Importa destacar, no entanto, que esse quadro não foge à regra do conjunto da cidade e do Estado do Amazonas. Dados do IBGE, divulgados em 2016 no jornal Diário do Amazonas, indicam que 58, 6\% dos trabalhadores do estado estavam atuando no mercado informal do trabalho em 2015, observando-se uma escala sempre crescente desse segmento.

Em 2013, do total de pessoas com mais de 16 anos que trabalhavam no Estado, 55,1\% atuavam no mercado de trabalho informal. Esse número aumentou para $57,5 \%$, no ano seguinte. Em 2015, chegou a $58,6 \%$ o número de trabalhadores que atuavam no mercado informal no Estado. (Jornal Diário do Amazonas, portal@d24am.com. Publicado em 02 de Dezembro de 2016)

Além disso, o estudo revela que os maiores índices de trabalhadores informais nesse mesmo ano (61\%) eram negros ou pardos e recebiam 80,9\% a menos que os trabalhadores com carteira assinada. Apesar da matéria destacar que entre os anos 2005 e 2014 esses dois segmentos apresentavam uma escala ascendente de renda, em 2015 "houve uma queda de 4,6\% em relação ao ano anterior. O rendimento médio em trabalhos formais $(R \$$ 2.195) foi quase o dobro dos informais ( $\mathrm{R} \$ 1.174$ )" (idem, 02 de dezembro de 2016).

Scherer (2004), em estudo sobre o desemprego, trabalho precário e descidadanização na Zona Franca de Manaus, situa o aumento da informalidade do trabalhador manauara articulado às necessidades de expansão da economia internacional, quando da reestruturação do modelo capitalista brasileiro em meados da década 1990. Esse conjunto de variáveis incidiu diretamente na diminuição de postos de trabalho formal na cidade de Manaus, embora sublinhe que o desemprego estrutural não se tratava naquele momento de uma novidade. Scherer explica que apesar da Zona Franca ter figurado durante seus anos dourados (1970 e 1980) como um potencial empregador dos migrantes - ex trabalhadores rurais, recém- 
chegados do interior do Amazonas - desde então já excluía grande parte desse segmento que não se adequava ao perfil desejado pelas indústrias. Assim, homens e pessoas com mais de 25 anos sempre foram consideradas inaptos para o trabalho nas linhas de montagem do distrito, pois as indústrias:

[...] incorporam no seu processo produtivo um número expressivo de trabalhadores desqualificados, jovens, dóceis, predominantemente do sexo feminino de acordo com a exigência do processo produtivo na época. Mas deixou de fora uma população trabalhadora supérflua, não incorporada: as necessidades médias da expansão do capital (MARX, 1975, p. 485). Os postos de trabalhos criados não foram suficientes para incluir a demanda de trabalhadores e as consequências mais visiveis foram o desemprego e o crescimento do setor informal. (SCHERER, 2004: p.129)

Com o ajuste neoliberal no início dos anos 1990 que permitia a abertura comercial exterior, possibilitando a redução de tarifas de importação sobre as indústrias da ZFM e, por consequência, a maior concorrência entre os produtos produzidos na Zona Franca e similares importados disponiveis no mercado nacional, houve um decréscimo expressivo da mão de obra industrial conforme demonstram os dados da Suframa destacados pela autora.

A partir dos anos 90, percebe-se um decréscimo do emprego nas indústrias do ZFM. Em 1991, o processo produtivo contava com 58.875 trabalhadores; em 1996, cinco anos após, com 48.090 e encerrou o último ano do milênio com 39.652 empregos no Distrito Industrial. Isto significa dizer que na década de 90, a Zona Franca de Manaus excluiu do processo produtivo 37.146 trabalhadores, ou seja, uma média de 3.740 por ano. (SCHERER, 2004: P.131)

Em sintese, o processo de reestruturação produtiva e o advento da automação da linhas de montagem, além do quadro de recessão por que passava o país no início da década de 90, são variáveis que conduziram à escassez de postos de trabalho no distrito industrial e empurraram o ex trabalhador formal - considerado agora velho demais e desqualificado para retornar às atividades que desempenhava - para o mercado informal, seja abrindo pequenos comércios em suas casas com o dinheiro da rescisão, ou migrando para outra área da informalidade que não requer muita qualificação. Um quadro, aliás, muito comum na pequena localidade estudada. Scherer sublinha, ainda, que a perda de emprego relacionada à mão de obra desqualificada na cidade de Manaus, tem um peso maior que 
na região Sudeste do país, onde o trabalhador é assimilado com maior facilidade para sua realocação no mercado de trabalho.

Tem-se no presente, espaços inteiros de moradia na periferia de Manaus, demarcados pela grande leva de trabalhadores informais, alienados de seus direitos trabalhistas e vivendo do jeito que podem. A localidade do entorno do igarapé na baixada da comunidade Santa Clara em Petrópolis é um desses espaços de moradia com grande concentração de trabalhadores do mercado informal, cuja trajetória pessoal e profissional correspondem a esse percurso traçado por Scherer (2004). Como se verá adiante neste texto, a relação que os moradores da baixada desenvolvem com o trabalho opera como um dos elementos de diferenciação entre si, na mesma medida em que as figurações "trabalhador formal" e "trabalhador informal" são utilizadas para demarcarem os melhores posicionados e os mais desclassificados no espaço social (Bourdieu, 2007) ${ }^{6}$.

\section{Especificidades Amazônicas: sobre violências simbólicas e o incentivo à cultura do trabalho}

Um marcador de composição da localidade identificado no transcurso da pesquisa foi a origem de seus moradores: são predominantemente amazonenses, da capital e interior. Esse dado não pode ser interpretado como uma coincidência, mas sugere que talvez essa condição represente um marcador estigmatizante para esses dentro do próprio estado e/ou cidade de origem. Afinal, é uma experiência comum em Manaus escutar os chavões: “amazonense é preguiçoso" ou “amazonense é acomodado", utilizados para justificar a posição subalterna dessa população dentro de seu próprio estado ou cidade de origem. Quantos manauaras podem garantir que nunca foram interpelados em função de uma associação à imagem do indígena de maneira pejorativa, reduzidos a serem incivilizados, ainda que sequer apresentem um fenótipo socialmente relacionado a esses povos? A pecha de "preguiçoso" e "acomodado" é utilizado muitas vezes para justificar o ambiente precário a qual estão associados, pessoas não dispostas ao trabalho.

\footnotetext{
6 Considero a existência de subgrupos justapostos em diferentes posições possíveis no espaço, estreitamente inseridos nos sistemas de disposições (habitus) característicos das diferentes classes e frações de classe, conforme entende Bourdieu.
} 
- Como se está tratando de um contexto amazônico, é importante trazer as considerações de Silva (1996), ao explicar como essa cultura do trabalho foi inculcada nas populações amazônicas, ainda em estágio de colonização e processo de destribalização, fazendo com que o então indígena passasse a compreender as ideias de trabalho e honra como sinônimos, em oposição ao ócio ao qual foram associados pejorativamente pelo colonizador. Considerando, entretanto, conforme afirma Silva (1996), que esse disciplinamento não obtivera os resultados esperados, observo que pode ainda estar em processo, na medida em que o manauara resiste, ao seu modo, aos discursos de competição e empreendedorismo atuais e, por isso, recebe a pecha de "acomodado". Mas, no escopo do discurso dominante primeiro, lançado sobre os povos amazônicos, depreende-se que:

O trabalho é um bem espiritual e temporal, principio que orienta a utilidade do índio para si próprio, para que contribuam no sólido estabelecimento do Estado e para o progresso dos moradores, das aldeias e das povoações. A ambição deve ser incutida como medida de combate ao ócio e à pobreza. O dever do trabalho corresponde à expectativa de honra e ascensão social. Persuadidos dessa máxima, os índios dar-se-ão conta da utilidade do trabalho e dos prejuízos da ociosidade. (SILVA, 1996. p:73)

O ócio, constitutivo do estilo de vida do indígena, passa a ser associado a atributos depreciativos no contexto de seu processo civilizatório, o que nos leva a compreender a necessidade do trabalho para afirmação e realização pessoal como parte de um processo cultural, dinâmica que põe em questão o caráter ontológico do trabalho. Considerando a construção social do processo valorativo do trabalho, observa-se a formação das escalas de classificação hierárquicas, de modo que o grau de honradez do indivíduo passa necessariamente pela relação que desenvolve com o trabalho. Se for para utilizar o contexto da localidade como um paradigma empírico, tem-se suas escalas de (des) valorização calcadas na relação com o trabalho nos seguintes termos: como há grupos associados a atividades licitas e ilícitas, em uma posição de base está o acesso ao trabalho lícito, ainda que informal (considerado inferior, mas digno); em seguida, de forma mais privilegiada, se vê o acesso ao trabalho lícito e formal. Aliás, existe todo um significado circular pelos becos com a farda ou crachá de uma empresa, seja ela qual for, significa que o indivíduo foi capaz de ser aceito socialmente em outros 
meios, demonstra um diferencial diretamente ligado ao caráter, uma espécie de moralização do trabalho. Mas, abaixo dessas escalas estão aqueles sem acesso à atividade laborativa reconhecida pelo meio enquanto tal, os ditos "desocupados" (um termo que comporta um grupo amplo e heterogêneo de indivíduos não inseridos no mercado de trabalho). A partir de tais critérios vão se estabelecendo as nuances grupais dos mais honrados ou desonrados, de modo tal que o termo "desempregado" deixa de ser uma condição temporal e passa a ser um atributo. Então, é nas diferentes formas de relação do morador da baixada com o trabalho, que reside um importante critério de diferenciação e desclassificação social.

\section{As diferentes relações com o trabalho: uma escala descendente, cujo limite é a condição marginal}

Em campo foi possivel encontrar uma gama de trabalhadores informais (pedreiros e auxiliares, domésticas, flanelinhas, eletricistas, camelôs, mototaxistas); pequenos e médios comerciantes dos mais variados tipos de mercadoria (roupa, estiva, alimentos). Esse grupo caracterizado em sua essência pelo baixo capital escolar, acaba por encontrar na ação microempreendedora ou no trabalho autônomo, sua fonte de renda. Observe-se, no entanto, que não está em questão o juízo de valor desse segmento em relação às vantagens ou desvantagens de suas atividades laborativas - se estão nesse campo de atuação por opção ou por falta dela mas, sim o fato de terem pouco capital escolar, de tal modo que essas atividades laborativas operam, antes, como uma saída viável e em alguns casos (sobretudo, no caso de alguns comerciantes) mais atrativa economicamente. Esse grupo pouco dissocia sua imagem do ethos do morador da localidade, pois figuram como o tipo que mais vive o cotidiano e as sociabilidades comum nos becos. Muitas vezes, seu espaço de trabalho é uma extensão de sua casa, seja no caso das tabernas, oficinas, mercadinhos, salões de beleza etc. Seus corpos também são uma extensão do lugar em que moram, pois, revelam em sua imagem traços do ambiente.

Há, por outro lado, um segmento de trabalhadores, aqueles inseridos ou com potencial para o mercado formal, que desempenham diferentes funções com diferentes níveis de formação escolar, seja no comércio ou na 
indústria. Encontra-se desde auxiliar de serviços gerais, cuja formação necessária restringe-se ao ensino fundamental; vendedores e operadores de caixa, montadores do distrito industrial; profissionais esses com grau de escolaridade que varia entre Ensino Médio completo e incompleto. Há profissionais de nível técnico, como gerente de loja e profissional técnico em contabilidade que atua em agência bancária, cujos títulos pomposos obscurecem a condição de um profissional mal remunerado, por vezes, com renda inferior aos autônomos e comerciantes. Grande parte dos moradores que está nesse grupo de trabalhadores formais não vive de forma tão presente o cotidiano da localidade. Sobretudo, os trabalhadores do comércio, devido à jornada de trabalho. Entretanto, assim como o grupo de trabalhadores informais, nesse grupo também há matizes. Observe-se que há profissionais de nível superior, como é o caso de uma servidora pública concursada que hoje vive com um salário acima da média da localidade e profissionais com o mesmo nivel de formação atuando em suas áreas no segmento privado. E ainda nesse matiz, encontra-se profissionais de formação superior que ainda não exercem a profissão para qual se formaram, cuja dificuldade de inserção em suas áreas de atuação faz com que continuem exercendo cargos de nível médio - encontram-se "desprovidos do capital social necessário para obter o pleno rendimento de seus diplomas", Bourdieu (2007, p.142) e acabam por engrossar a fila de diplomados cuja formação acadêmica parece não ter sido o suficiente para garantir uma vaga no mercado compatível com sua formação.

Outra gradação grupal da localidade diz respeito àqueles que estão à margem da formalidade e da informalidade laborativa - os indivíduos marginalizados de forma generalizante: os "desocupados". Alguns associados apenas ao ócio, outros a práticas ilícitas - quando essas duas interpretações não são lançadas juntas sobre um mesmo sujeito. São eles designados por diferentes termos: "vagabundos", "ladrões", "traficantes", "cachaceiros", "piriguetes" (no caso de mulheres, cabendo aqui a possibilidade de prostituição) etc. Esses parecem ter se adequado à expectativa social lançada sobre o espaço social imputado à localidade e operam como demarcadores da baixada com sua forma de falar e vestir, enfim, todo seu 
estilo de vida. São caracterizados por constituírem seu cotidiano quase que totalmente na localidade assim como os autônomos e comerciantes, mas diferentes desses, não têm suas figuras ligadas a uma ocupação laborativa. Estão quase que diuturnamente marcando presença no espaço público da localidade, sentados nas laterais dos becos, conversando em grupos. Há mulheres também, talvez até em maior número, que se encaixam nessas características, mas, por uma questão de desigualdade de gênero ${ }^{7}$, o desprezo por essa condição afeta mais frontalmente aos homens. Certa vez, foi possível ouvir de um deles uma brincadeira quanto à sua condição: "essa é a rua dos desempregados". Na ocasião, a rua estava com uma fila de homens de idade adulta sentados na calçada. Entendendo que há uma escala social de classificação utilizada pelos moradores da baixada para interpretarem seu espaço de moradia, esse último grupo repleto de pluralidade parece configurar como os outsiders dos outsiders, se recorrermos aos termos de Norbert Elias, ou a ralé, se considerarmos os estudos de Souza (2009) sobre as classes no Brasil.

O processo de modernização brasileiro constitui não apenas as novas classes sociais modernas que se apropriam diferencialmente dos capitais cultural e econômico. Ele constitui também uma classe inteira de indivíduos, não só sem capital cultural nem econômico em qualquer medida significativa, mas desprovida, esse é o aspecto fundamental, das precondições sociais, morais e culturais que permitem essa apropriação. É essa classe social que designamos neste livro de "ralé" estrutural, não para "ofender" essas pessoas já tão sofridas e humilhadas, mas para chamar a atenção, provocativamente, para nosso maior conflito social e político: o abandono social e político, "consentido por toda a sociedade", de toda uma classe de individuos "precarizados" que se reproduz há gerações enquanto tal. Essa classe social, que é sempre esquecida enquanto uma classe com uma gênese e um destino comum, só é percebida no debate público como um conjunto de "indivíduos" carentes ou perigosos, tratados fragmentariamente por temas de discussão superficiais, dado que nunca chegam sequer a nomear o problema real, tais como "violência", "segurança pública", "problema da escola pública", "carência da saúde pública", "combate à fome" etc. (SOUZA, 2009. p: 21)

Há, na verdade, um grande contingente de indivíduos inaptos ao mercado formal de trabalho e que não se reconhecem na modalidade "empreendedora", e parecem seguir sem perspectiva de alteração de sua

\footnotetext{
7 Às mulheres que estão sem trabalhar, cabe também serem lidas como "dona de casa", ou "mãe" que dedica cuidados ao filho. Não ter ocupação laborativa fora de casa e, portanto, autonomia financeira, tem sido apontado como um dos indicadores da submissão da mulher à violência doméstica, mas essa torna-se uma condição "aceitável".
} 
realidade. Os "desocupados" correspondem, com efeito, a um grande contingente de desempregados que recebem todos os simbolismos negativos de sua condição, uma vez que no contexto popular o "trabalho" representa um elemento valorativo do indivíduo. Além disso, do ponto de vista da aparência, é tênue a linha que os separa daqueles que desenvolvem práticas ilícitas, mesmo porque não há um confronto direto na localidade entre "bandidos" e "trabalhadores" como está posto no subtópico seguinte - e ainda que houvesse, não se encaixariam nesse segmento "trabalhador". Observe-se, portanto, que não há dois grupos estanques de "trabalhadores" e "bandidos", mas nuances que vão se justapondo em escalas e que se confluem num mesmo território, num mesmo espaço social, sem necessariamente se reconhecerem numa mesma identidade coletiva.

\section{Novas figurações: em vez da oposição "trabalhador versus bandido", a interlocução "trabalhador/bandido"}

O clássico estudo de Zaluar (1985) sobre a favela carioca Cidade de Deus permite identificar alguns elementos-chave de discussão sobre espaços de moradia popular reconhecidos no contexto da cidade como "favelas" e que, assim como seu lugar estudado, são manchados pelo estigma de "lugar perigoso". Dentre esses elementos, é necessário pontuar as estratégias de diferenciação e dinâmicas internas de convivência entre diferentes nuances desses grupos sociais. Embora, tratar desse aspecto da forma como fora depreendido em campo pode, com efeito, cair no plano das generalizações, tanto de minha parte enquanto observadora - e por isso dou grande importância às minúcias da descrição tentando transmitir informações para além do aparente -, quanto de possiveis interpretações enviesadas da parte de quem lê, podendo conduzir ao entendimento simplificado de que todos que moram na localidade são de fato pessoas com algum desvio moral ou associado direta e propositalmente a práticas ilícitas. Importa frisar, entretanto, que fora observado em campo uma interlocução direta entre precariedade de moradia e a precarização do trabalho, a tal nível que há outro ponto de interseção que se forma diante dessa interlocução: o hibridismo da figura do "trabalhador", por outros motivos que não aqueles 
trazidos por Zaluar, mas pelo fato dessa categoria passar a comportar certas ilicitudes associadas a "bandidos", considerando, no entanto, que hajam, por implicação, outras dinâmicas e as mais diversas reações, todas calcadas na necessidade de estabelecer uma relativa harmonia no ambiente de moradia.

Observe-se que, segundo Zaluar, no caso da favela Cidade de Deus, a relação bandido/ trabalhador se dava de maneira híbrida e complexa, na medida em que a figura do "bandido" mostrava-se ambígua quando da convivência comunitária, era por vezes, temido e querido ao mesmo tempo. Zaluar demonstra como, no contexto dos anos 1980, era bem demarcada a imagem do "bandido" e do "trabalhador" da história, ainda que convergissem em termos de convivência e objetivos comunitários, poderia acontecer, inclusive, que os moradores "trabalhadores" desenvolvessem um sentimento de afeto e se sentissem protegidos pela figura do "bandido". Entretanto, no caso Manauara, essa dinâmica não existe.

Pelo que pude observar, se há hibridismo na relação bandido/trabalhador na localidade, ele se dá pelo fato de em certos casos não haver, de maneira tão demarcada, as imagens do "trabalhador" e do "bandido", não nos termos identificados por Zaluar, para quem a identidade do "trabalhador", via de regra, foi construída socialmente por oposição aos "bandidos" e "vagabundos", cuja característica maior é o fato de não trabalharem. Há ocasiões em que o trabalhador, seja do mercado formal ou informal, desempenha tanto um "personagem" quanto o outro: pode um homem ser trabalhador do Distrito Industrial, mas não deixar de desempenhar suas atividades ilícitas, sem causar, por isso, muita estranheza quando da convivência com o restante dos moradores "não envolvidos". Embora existam alguns moradores do sexo masculino que parecem fazer questão de se demonstrarem inseridos em alguma atividade ilícita, para quem não tem relação nenhuma com os meandros dessas atividades, fica obscura a demarcação de quem de fato desenvolve algum papel na dinâmica dessas atividades (desde os menos importantes como "aviãozinho"8, ou "olheiro"9 até as posições de liderança, se há) e aqueles que

\footnotetext{
8 Pessoa responsável em realizar pequenas entregas de drogas ilícitas, sem necessariamente ser o agente principal do comércio de drogas.
} 
estão apenas a conviver em relação próxima ou tentar valer-se da imagem do "bandido" para algum fim. Contudo, é nítido o fato de que todos eles interagem de modo semelhante a qualquer outro grupo de moradores: com o cuidado de não excederem certos limites de convivência comunitária, o que, de certa forma, permite serem assimilados sem grandes conflitos por parte do restante da comunidade. Eu diria que a regra é ignorar, sempre que possivel, o que outros estão ou podem estar fazendo de ilícito, seja nas ruas, seja dentro de casa.

Destaque-se que, embora a possibilidade dessa interlocução entre a figura do bandido e trabalhador num mesmo individuo (desempenhando atividades associadas a cada um desses personagens sociais) tenha sido inferida em campo, esse dado não deve servir para reduzir o conjunto de moradores a apenas essa possibilidade. Aqueles que são considerados trabalhadores sem nenhum envolvimento com atividades consideradas ilícitas são bem demarcados entre os comunitários, como se verá adiante.

Quando se trata dessa relação conflituosa trabalhador/bandido, se há uma tensão, é a discrição e as regras de boa convivência que permitem certa tranquilidade nos ares da localidade, sem que necessariamente haja a presença de armas de fogo no cotidiano desse espaço - ao menos não no campo de visão de todos - como instrumento demarcador de posição e poder. Essa informação entra em contraste com o que Zaluar apresenta sobre o contexto da Cidade de Deus, ao explicar a arma de fogo como elemento-chave da classificação reconhecida pelos moradores daquela favela que opõe a figura do "bandido" à do "trabalhador". Segundo ela, mais que apenas uma oposição lógica em um sistema classificatório: "Colocar uma arma na cintura tem, entre eles, o sentido de declarar publicamente uma opção de vida e de passar a ter com a população local relações marcadas pela ambiguidade e abertas ao conflito" (ZALUAR, 1985: p. 146).

Diferente do cotidiano carioca descrito por Zaluar, marcado por conflitos abertos, nas ruas, envolvendo traficantes e policiais, ou o confronto

\footnotetext{
9 Responsável em vigiar a dinâmica e o cotidiano do lugar. Na periferia estudada, essa posição não implica em uma postura de confronto em relação aos demais moradores, tampouco imposição por arma de branca ou de fogo, mas em se posicionar em determinado ponto do lugar observando o movimento por longas horas.
} 
armado entre os moradores envolvidos com o tráfico; não há na localidade uma rotina de atos violentos que conduza à violação da integridade fisica dos moradores, seja envolvendo vizinhos ou a polícia. $\mathrm{Na}$ localidade estigmatizada em Manaus, é absolutamente inexistente a cena de alguém circulando pelos becos empunhando arma de fogo (seja revólver ou fuzil) com o objetivo de demarcar território, nem mesmo aqueles reconhecidos pelos outros moradores como sendo envolvidos com o tráfico de drogas. Se existem armas de fogo na localidade, essas não são expostas em meio à disputa por território entre "bandidos" ou em conflito direto com a polícia, ou como marcador da relação "bandido" / "trabalhador".

\section{V "Incapacidade" intergeracional: dos pais, trabalhadores precarizados do mercado lícito, aos filhos trabalhadores do mercado ilícito.}

Há uma família da baixada que representa bem a categoria "desocupado" em suas diferentes expressões, a "família dos ratos". São assim identificados em função da grande quantidade de pessoas que compõem o núcleo familiar, além de serem todos muito parecidos uns com os outros. Na verdade, "rato" geralmente opera como adjetivo atribuído àqueles indivíduos cujos núcleos familiares são numerosos e que muitas vezes servem de piada para os outros moradores. No caso em questão, quando crianças, esses mesmos rapazes que hoje sugerem "perigo", eram tratados pela vizinhança com certa zombaria. Sempre foram franzinos e alguns apresentavam dificuldade na fala, além de ser conhecido, pelos demais moradores, o fato dessa família ter poucos recursos financeiros para manutenção do básico, como roupas e alimentação. Os pais trabalhavam informalmente, eram vendedores ambulantes de lanche ou picolé; as mães sempre foram "do lar", nada diferente do contexto presente. Pouco se consegue visualizar a casa onde moram, coberta por uma cerca de madeira reutilizada, na margem do rip rap ${ }^{10}$. Ainda adolescentes, os meninos tiveram problemas com a polícia em função de sua associação à venda de drogas e outras práticas ilícitas. Mesmo dentre esses, não se sabe ao certo quem

\footnotetext{
10 Termo geotécnico. Consiste em solo ensacado para contenção de erosões, no caso em questão faz parte da estrutura de drenagem do igarapé, pequeno curso d'água que perpassa a localidade estudada. Ultimamente quando alguém se refere a algo próximo ao igarapé, por vezes, utiliza o termo técnico "rip rap" em vez de seu nome original. Algo do tipo: "ele mora bem ao lado do rip rap".
} 
pratica ou não esse tipo de atividade, apesar de que parecem fazer questão de serem compreendidos como tais. Conversam em voz alta sobre a experiência própria e de seus conhecidos, narrando alguns eventos de abordagem policial, de calote quanto ao pagamento que lhes é devido, podendo-se ouvir inclusive relatos sobre o stress relacionado à sua rotina de trabalho - é assim que demonstram compreender a atividade que exercem. Tornaram-se trabalhadores precarizados informais disponíveis para a atuação no campo de atividades ilícitas. Observa-se, portanto que não apenas não conseguiram ascender socialmente, mas decaíram algumas escalas no campo da desclassificação social.

Pode-se tentar compreender o quadro em que se insere tal família e como são compreendidos em face dos demais moradores aptos ao mercado de trabalho lícito e formal, a partir dos estudos de Souza (2012. p: 47-48) sobre classes sociais no Brasil, ao identificar os matizes sociais que emergiram nos últimos anos no contexto da classe trabalhadora, distribuídos em setores denominados por ele de "batalhadores" e "ralé". Ele identificou, logo abaixo da classe média, um setor da classe trabalhadora que se soergue em contexto mais recente, aspirantes à pequena burguesia empreendedora brasileira: os batalhadores. Para o autor, esses são, com efeito, os beneficiários em potencial dos projetos de "capacitação" e de ampliação de "oportunidades" característicos das gestões petistas da última década. Composto em sua grande maioria por trabalhadores relativamente estáveis e capacitados, cuja relativa ascensão social fora conseguida por meio de muito esforço pessoal.

Há, porém, outra classe social identificada por Souza, composta por indivíduos que até têm, na grande maioria das vezes, a mesma origem empobrecida dos batalhadores, mas que apresentam limitações que estão para além do aspecto econômico. O setor denominado por ele de ralé brasileira, situado abaixo dos batalhadores, se mostra tão bloqueado ao acesso de bens que lhes possam proporcionar meios de ascensão social, que sequer os programas sociais que lhes foram direcionados conseguiram dar conta de suas mazelas. Segundo ele, é tênue a linha que separa esses dois 
subgrupos, posto que ambos comungam da mesma origem, mas ao mesmo tempo, é evidente que ambos conseguem chegar a resultados diferentes.

\section{Considerações finais}

Toda pesquisa está passivel de limitações e esta não é diferente. Entretanto, penso que a contribuição desta discussão, consiste no repensar as formas de compreensão do que se convencionou chamar de "classe trabalhadora", até então pensada de maneira unívoca e como um elemento fomentador de unidade, de sentimento de pertença. Por meio da presente pesquisa é possível pensar que, em um contexto neoliberal, onde há um grande contingente de desempregados e pessoas inaptas ao trabalho, a figuração trabalhador opera mais como critério de diferenciação que necessariamente um elemento de unidade. Ao mesmo tempo, observa-se que a existência de postos de trabalho ainda que mal remunerados, parecem conceder certa dignidade aos grupos sociais pertencentes às classes populares. Isso implica em considerar a existência atual de não apenas uma classe trabalhadora, mas de pelo menos duas subclasses (os formais e informais), que ao mesmo tempo em que são distintas, também são constituídas por demais gradações, além de, por vezes, posicionarem contrariamente em face das mesmas demandas, na defesa de interesses diferentes ${ }^{11}$.

As relações de alteridade presentes no contexto de um determinado espaço de moradia popular, pautadas na relação que esses grupos sociais desenvolvem com o trabalho, devem ser consideradas, não cabendo mais um discurso unívoco. Para um determinado morador, ser considerado pertencente a uma mesma classe de outro que lhe parece inferior, pode

\footnotetext{
11 Os anos em que desenvolvi a pesquisa foram marcados por inúmeros conflitos político - ideológicos no país, acontecimentos esses passiveis de diferentes interpretações, cujo resultado final foi a retirada da presidenta eleita, Dilma Rousseff no ano 2016, após um processo extremamente questionável de "impeachment". Mas, o que é importante ressaltar: salta os olhos a pouca adesão do trabalhador manauara às manifestações que diziam lhes representar, o que parece acontecer não apenas pela campanha de criminalização dos movimentos sociais associados à esquerda. É patente a não identificação dos trabalhadores informais com atos como "Greve Geral" promovidos na cidade por movimentos sociais e sindicados. Desses acontecimentos, é possivel observar esses dois grupos bem demarcados: enquanto os trabalhadores formais faziam greves reivindicando a garantia de direitos sociais históricos, a parcela de trabalhadores informais (ou seja, a grande maioria dos trabalhadores de Manaus) continuavam suas labutas individuais cotidianas, indiferentes ao discurso de "greve" enquanto meio de conquista de direitos. Fazer greve contra quem, se são trabalhadores precarizados de si mesmos?
} 
operar como uma ofensa pessoal e proporcionar uma postura de resignação e distanciamento de qualquer tentativa de formação de coletivo. Como comunicar a necessidade de formação de um coletivo para além das estratégias individuais de fuga da desclassificação social, é uma questão pertinente e que não deve ser ignorada.

Mas, o presente texto também trouxe outra discussão central, a maneira como as relações de alteridade que se processam mediante a categoria trabalho atua diretamente na reprodução de estigmas territoriais imputados a determinados espaços na cidade. A medida que os sujeitos sociais se utilizam da figuração "trabalhador" para demarcarem-se como sujeitos mais valorosos que a grande maioria inapta ao mercado de trabalho formal, reforçam mais ainda a personificação da culpa nos próprios desprivilegiados, pelas mazelas que lhes acometem, evidenciando a condição de incapacidade e desvalorização associada a esses sujeitos sociais e, por implicação, a demarcação do espaço como propício a indivíduos de segunda categoria, como o "reduto dos párias". Nesse sentido, é tênue a linha que separa um trabalhador considerado de segunda categoria, de um "vagabundo" ou "desocupado". Além disso, o discurso valorativo do trabalho parece legitimar as assimetrias sociais e os valores individualistas, ao contrário do que se pretende, quando se usa o termo "trabalhador", pensando estar tratando de uma tentativa de formação de unidade. Poderia assim ser se a percepção dominante não fosse permeada por valores individualista neoliberais.

Há, ainda, para além de grupos distintos de trabalhadores, aqueles que sequer se encaixam nessa categoria. São os ditos "desocupados" (alguns com problemas de dependência de álcool e de outras drogas ilícitas), mas que acabam operando como uma espécie de "faz-tudo" ao realizarem pequenos serviços mal remunerados para os outros moradores que não querem executá-los, ainda que não sejam compreendidos pelos outros moradores como um "trabalhador". A figura do "desocupado" abrange uma gama grande de perfis dos moradores da baixada, todos julgados a partir do parâmetro do acesso ao trabalho e de sua licitude. Alguns desses, ao reproduzirem o comportamento delinquente associado ao "lugar perigoso", 
submetem-se às expectativas sociais lançadas sobre si e os seus, e adequam-se enquanto órgão constituinte do "lugar" a eles imposto. São eles determinados pelo "outro" (olhar de fora), pelo estado inalterado das coisas, pela sociedade que, incauta, os produzem enquanto "marginais", mas que ao mesmo tempo são desejosos pela sua inexistência. Não deixam de ser uma espécie de "trabalhador precarizado", mão-de-obra barata para o comércio de atividades ilícitas.

\section{Referências}

BOURDIEU, Pierre. A distinção: crítica social do julgamento. Trad. Daniela Kern \& Guilherme Teixeira. São Paulo/Porto Alegre: EDUSP/Zouk, 2007.

ELIAS, Norbert; SCOTSON, John L. Os estabelecidos e os outsiders: sociologia das relações de poder a partir de uma pequena comunidade. Tradução de Vera Ribeiro. Rio de Janeiro: Jorge Zahar, 2000.

SCHERER, Elenise Faria. Desemprego, trabalho precário e descidadanização na Zona Franca de Manaus. Revista Somanlu. Manaus. Ano 4, n.1, p. 125-145, 2004.

SILVA, Marilene Corrêa. O Paiz do Amazonas. Manaus. Editora da Universidade do Amazonas, 1996.

SOUZA, Jessé. Ralé brasileira: quem é e como vive / Jessé Souza; colaboradores. André Grillo ... [et al.] - Belo Horizonte: Editora UFMG, 2009.

Os batalhadores brasileiros: nova classe média ou nova classe trabalhadora? 2 ${ }^{\mathrm{a}}$ Ed. rev. e ampl. / Jessé Souza; colaboradores Brand Arenari [et al.]. - Belo Horizonte : Editora UFMG, 2012.

ZALUAR, Alba. A máquina e a revolta. Organizações populares e o significado da pobreza. São Paulo. Editora Brasiliense, 1985. 